\title{
Comparative Analysis on Buckling Behavior of Steel Cylindrical Tanks by Consideration of More Realistic Numerical Models
}

\author{
A. R. Shokrzadeh ${ }^{1}$, F. Mansuri ${ }^{1}$, M. Asadi ${ }^{1}$, M. R. Sohrabi ${ }^{2}$ \\ ${ }^{1}$ Engineering Department of Iranian Oil Pipelines and Telecommunication Company \\ Tehran, Iran \\ Shokrzadeh-a@ioptc.ir; Mansuri-F@ioptc.ir \\ ${ }^{2}$ Department of Civil Engineering, Shiraz University \\ Shiraz, Iran \\ Sohrabi@hamoon.usb.ac.ir
}

\begin{abstract}
Liquid storage steel tanks are vertical above-ground cylindrical shells and as typical thin-walled structures, they are very sensitive to buckling under external pressures, especially when they are empty or at low liquid level. In this paper the results of numerical investigations on the effects of spiral stairway on the buckling behavior of steel cylindrical tanks subjected to external pressures are presented. Furthermore, a numerical study is performed to investigate the effects of internal corrosion on the buckling behavior of ground based steel cylindrical liquid storage tanks, subjected to both wind and vacuum pressures. It is concluded that the spiral stairway acts as an oblique stiffener on the tank wall. Contrary to the case of wind loading, the stairway has negligible effect on buckling resistance of tanks under vacuum pressure. In addition, it is found that the buckling load is markedly reduced with thinning of the shell for upper part corrosion cases, irrespective of the loading condition.
\end{abstract}

Keywords: Buckling; Corrosion; Numerical investigation; Spiral stairway; Steel cylindrical tanks; Vacuum pressure; Wind pressure

\section{Introduction}

Above-ground, vertical tanks of cylindrical shape are constructed in industrial and agricultural plants to store various fluids such as petroleum, oil, fuel etc. They usually consist of a thin bottom plate, a cylindrical shell with uniform or stepped thickness and a closed-roof or open-top [1]. The occurrence of moderate damage to total failure under high wind speeds is mainly associated with buckling of cylindrical shell of the tank [2-8]. Different types of tanks have been investigated, like open-topped [9] and fixed-roof [10, 11 and 12], by combination of computational methods and experimental results. Jaca and Godoy [6] indicated that tanks failure can occur under moderate wind velocities during their construction. In addition, thin-walled cylindrical tanks are susceptible to buckling due to uniform external pressure [13]. If rapid discharge of tank accompanied by inadvertent closure of all tank valves will lead to a rapid drop in internal pressure and in severe cases, tank failure [14, 15].

Innovative ways of strengthening and improving buckling resistance have been studied in some recent papers such as Ref. [16] in which the additional buckling capacity of steel tanks caused by attached fiber reinforced polymers (FRP) retrofit layers was studied. In addition, a parametric study was conducted by Lewandowski et al. [17,18] to establish the influence of number and position of intermediate stiffeners on buckling capacity of the tank. In this paper, the buckling characteristics of tanks equipped with spiral stairway have been studied under vacuum pressure and various wind directions.

Corrosion of such welded structures may develop through various types of mechanisms and with various intensities. For oil storage tanks, the most dominant types are uniform and pitting corrosion. Groysman $[19,20]$ defined corrosion rates of different parts of aboveground storage tanks containing crude oil and petroleum products after 55-70 years of use in a table. The table shows that the corrosion rate of the tank section which is in contact with vapor phase (zone (I)) depends on the type of product stored and it is ranged from 0.1 to $1.5 \mathrm{~mm} / \mathrm{year}$. The presence of corrosive vapors, such as hydrogen sulphide mixed with moisture and air in vapor space of sour petroleum liquids tanks causes the zone (I) of such tanks be an area of significant corrosion [19-23].

\section{Structure Prototypes}

Three conical roof tanks models are considered for numerical investigations. The cylindrical part of the models have variable height, ranging from $\mathrm{H} / \mathrm{D}=0.4$ to 0.95 , with tapered thickness. All the models have a conical fixed roof supported 
by a number of rafters and columns. The tank geometries chosen (TK-a, TK-b and TK-c) are similar to those considered by Virella et al. [24]. The geometries of tanks TK-a, TK-b and TK-c are summarized in Table 1, which are representative of three tanks with aspect ratios of $0.40,0.63$ and 0.95 , respectively.

Table 1: Geometrical characteristics of tanks TK-a, TK-b and TK-c.

\begin{tabular}{cccc}
\hline Geometrical Characteristics & TK-a & TK-b & TK-c \\
\hline Shell Height $(\mathrm{m})$ & 12.191 & 19.337 & 29.103 \\
Roof Height $(\mathrm{m})$ & 2.858 & 2.858 & 2.858 \\
Tank Diameter $(\mathrm{m})$ & 30.48 & 30.48 & 30.48 \\
\hline
\end{tabular}

\section{Computational Models}

General purpose program ABAQUS [25] was used for finite element discretization of the structure. Eight-node shell elements with reduced integration were used for the cylinder, whereas triangular elements were employed on the roof (STRI65). Rafters were modeled by beam elements. ASTM A36 steel is assumed for all tank models.

\section{Wind Loads on Cylindrical Tanks}

The wind load is simulated as pressure distribution acting on the circumferential shell. According to AS-NZS 1170-2 Appendix C equations [26] the coefficient of wind pressure $C_{p}$ is given by:

$$
C_{p}(\theta)=k_{c} C_{p 1}(\theta)
$$

Where $\theta$ is the longitude measured from the windward ( $\mathrm{H}$ and $\mathrm{D}$ are the height and diameter of the tank). Factor $k_{c}$ takes the form

$$
\begin{gathered}
k_{c}=1.0 \text { for } C_{p 1} \geq-0.15 \text { or, } \\
k_{c}=1.0-0.55\left(C_{p 1}+0.15\right) \log (H / D) \text { for } C_{p 1}<-0.15 \\
C_{p 1}(\theta)=-0.5+0.4 \cos \theta+0.8 \cos 2 \theta+0.3 \cos 3 \theta-0.1 \cos 4 \theta-0.05 \cos 5 \theta
\end{gathered}
$$

\section{Influence of Spiral Stairway on Buckling Behavior of the Tanks with Conical Roof}

The tanks are modeled with, and without stairway. The slope angle of the stairway with respect to horizontal plane is approximately $44^{\circ}$. The circumferential stairway is simulated by an I-shaped section beam element (Fig. 1) supported by a number of brackets (L75x75x6). The beam flanges are the same as stringer plates of real tank stairway (PL6x210) and beam height is equal to real stairway tread length. In the rest of the paper, the superscript (s) or (o) shows that the constructed finite element model is "with stairway" tank model or "open-topped" one, respectively.
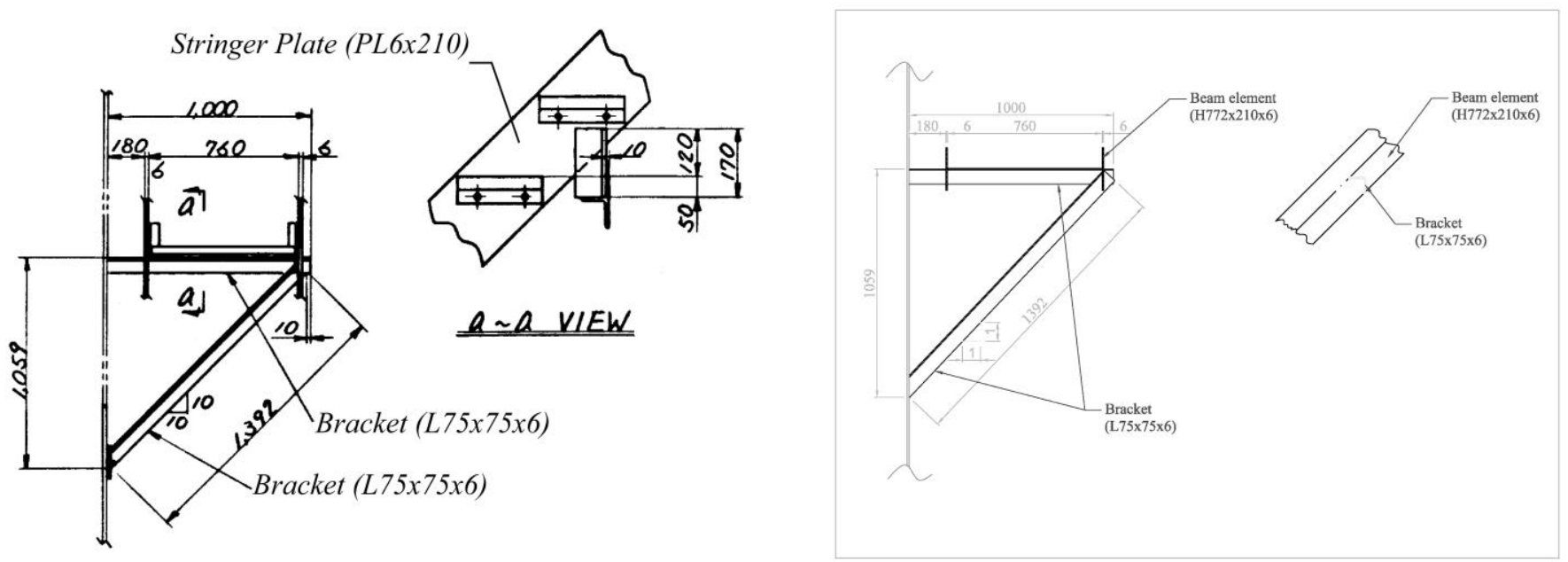

Fig. 1: Spiral stairway details of the real stairway (left side) and simplified model of the stairway (right side). 


\subsection{Tanks under vacuum pressure}

The relative difference of the first six eigenvalues of the tanks with and without stairway varies from 0.06 to $0.83 \%$. $0.83 \%$. Moreover, the maximum difference between the first eigenvalues is observed in the TK-b, which corresponds to to the tank with aspect ratio of 0.63 (Table 2).

Table 2: Critical buckling loads* obtained from bifurcation (eigenvalue) analysis

\begin{tabular}{|c|c|c|c|c|c|c|}
\hline \multirow{2}{*}{ Tank Models } & \multicolumn{6}{|c|}{ Modes } \\
\hline & $1 \mathrm{st}$ & 2nd & $3 \mathrm{rd}$ & 4th & 5th & 6th \\
\hline TK-a & 2.09 & 2.096 & 2.099 & 2.099 & 2.135 & 2.135 \\
\hline TK-a ${ }^{\mathrm{s}}$ & 2.09 & 2.097 & 2.112 & 2.115 & 2.14 & 2.142 \\
\hline $\begin{array}{l}\text { Relative Difference } \\
(\%)^{* *}\end{array}$ & $06^{0 .}$ & 0.072 & 0.634 & 0.762 & 0.225 & 0.290 \\
\hline TK-b & 2.99 & 2.999 & 3.010 & 3.010 & 3.021 & 3.022 \\
\hline TK- $\mathrm{b}^{\mathrm{s}}$ & 3.00 & 3.004 & 3.019 & 3.020 & 3.043 & 3.046 \\
\hline $\begin{array}{l}\text { Relative Difference } \\
(\%)^{* *}\end{array}$ & $167^{0 .}$ & 0.177 & 0.302 & 0.312 & 0.728 & 0.798 \\
\hline TK-c & 2.99 & 2.995 & 3.007 & 3.007 & 3.009 & 3.009 \\
\hline TK-c ${ }^{s}$ & 2.99 & 3.0 & 3.013 & 3.013 & 3.033 & 3.034 \\
\hline $\begin{array}{l}\text { Relative Difference } \\
(\%)^{* *}\end{array}$ & 140 & 0.150 & 0.193 & 0.206 & 0.804 & 0.831 \\
\hline
\end{tabular}

${ }^{*}$ All buckling loads are in $\mathrm{kPa}$.

*** Relative Difference $=\frac{\lambda_{c}^{s}-\lambda_{c}}{\lambda_{c}} \times 100 \%$

The deflected shape of tanks with spiral stairway resulting from the computations (Fig. 2) is also consistent with the buckled shapes shown in Fig. 3. As can be seen from Fig. 3, the buckling waves are not formed in locations around the stairway.

a

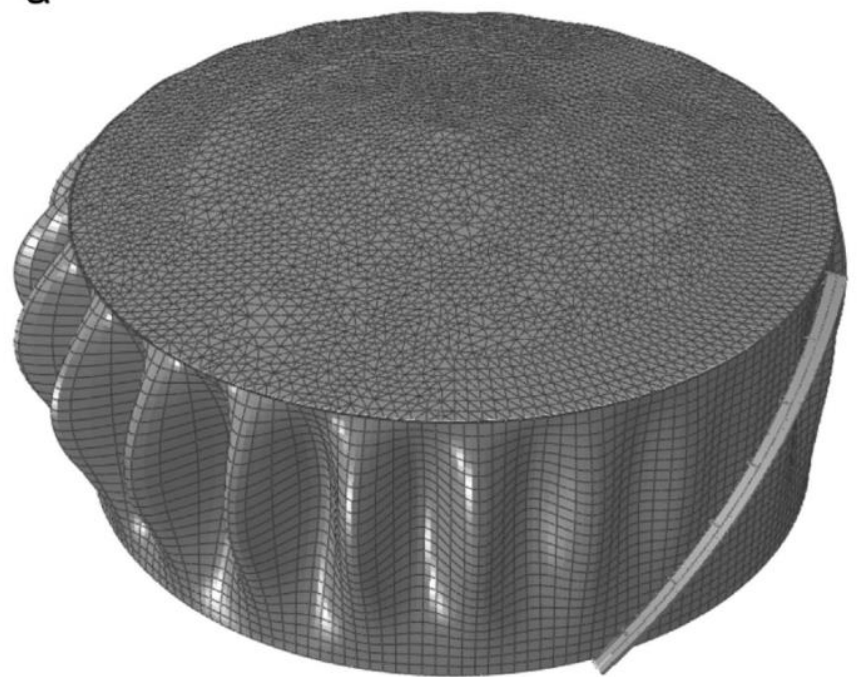

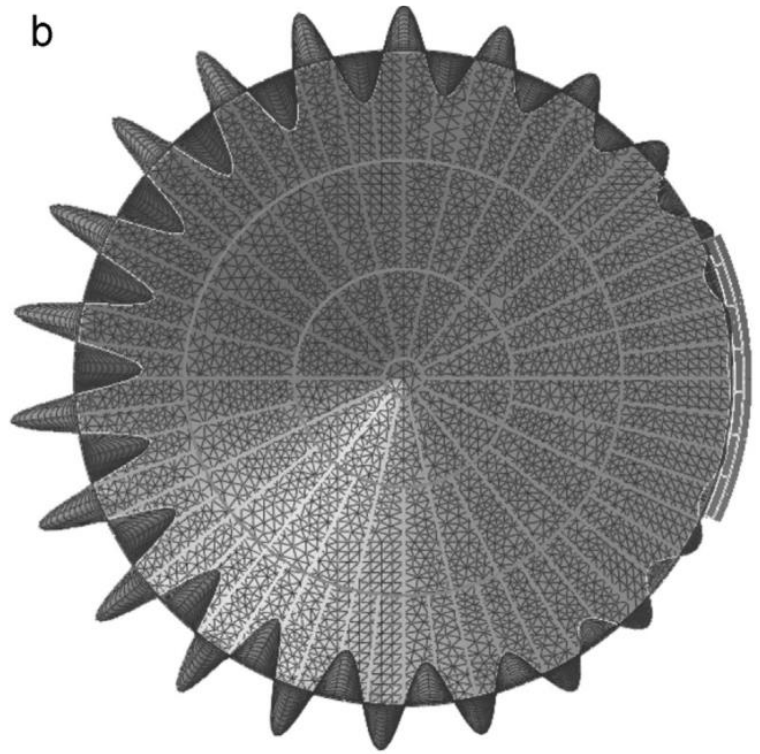

b

Fig. 2: First buckling mode of $\mathrm{TK}-\mathrm{a}^{\mathrm{s}}$ under vacuum pressure (isometric and bottom view) 


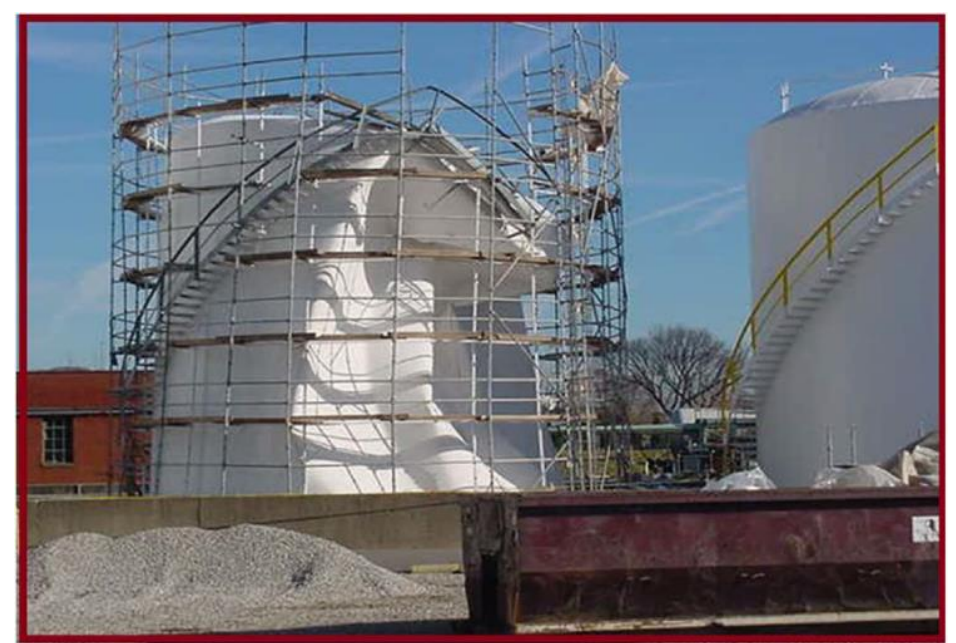

Fig. 3: Example of buckling of cylindrical tanks under vacuum pressure. This collapse occurred following accidental draining of the contents whilst the vacuum valve was blocked by plastic tape during paint refurbishment.

\subsection{Tanks under Wind Pressure}

To simulate effect of wind direction on tanks with spiral stairway, the direction of wind incidence is considered as a variable. For this purpose, wind directions characterized by angles ranging between $0^{\circ}$ and $360^{\circ}$ are investigated. Wind direction angle $(\alpha)$ is measured with respect to the line connecting the center of the stairway to the tank cylinder axis perpendicularly.

Clearly, the spiral stairway gives a positive reinforcement to the tank wall (see Fig. 4). The $\lambda_{c}=$ 2.87, 4.00 and $3.86 \mathrm{kPa}$ are the smallest eigenvalues of TK-a, TK-b and TK-c respectively, while $\lambda_{c}=$ $3.00,4.10$ and $4.71 \mathrm{kPa}$ are computed for TK-as-(10Deg), TK-bs-(20Deg), and TK-cs-(35Deg), respectively.

The effect of circumferential stairway on critical load of the tanks $\left(\left(\lambda_{c}^{s}-\lambda_{c}\right) / \lambda_{c}\right)$ for different wind directions is shown in Fig. 4. It can be seen that the buckling resistance of TK-a, TK-b, and TK-c $\left(\lambda_{c}\right)$ increases up to $13.5 \%$, $21.3 \%$ and $22 \%$, respectively, when spiral stairway is installed on them. Therefore, the effect of stairway on buckling resistance, increases from TK-a to TK-c, whose aspect ratio increases while their diameter is unchanged.

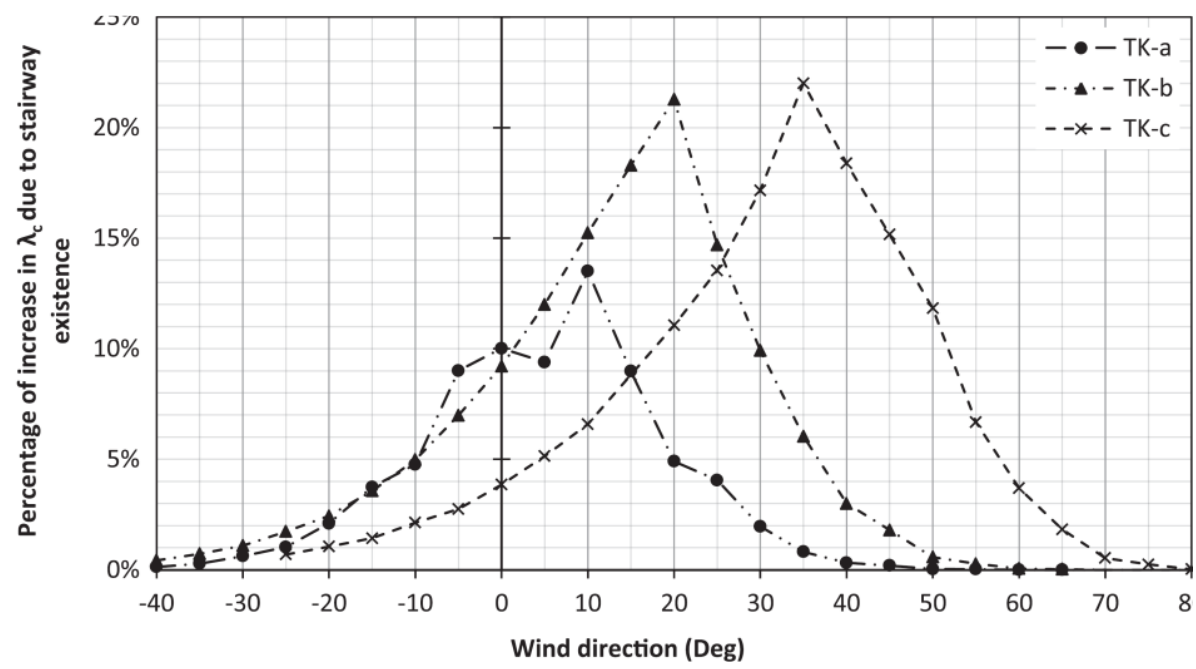

Fig. 4. Bifurcation analysis results of tanks: a comparative view of the TK-as, TK-bs and TK-cs buckling loads in different wind directions.

\section{The Effect of Upper Part of the Tank Corrosion on the Buckling Behavior of Tanks}

In the numerical analyses, the rate of thinning of the roof plate, roof supporting structure and upper $12 \%$ of the wall height is assumed $0.2 \mathrm{~mm} / \mathrm{yr}$. 
Details of the models thus created for simulation of TK-a are given in Table 3.

Table 3: Geometric properties of the cylindrical tanks considered for analyses under vacuum pressure.

\begin{tabular}{|c|c|c|c|}
\hline Model & Age (years) & $H / D$ & Reduced thickness (mm) \\
\hline TK-a-00.0 & 0 & 0.40 & 0 \\
\hline TK-a-02.5 & 2.5 & & 0.5 \\
\hline TK-a-05.0 & 5.0 & & 1.0 \\
\hline TK-a-07.5 & 7.5 & & 1.5 \\
\hline TK-a-10.0 & 10 & & 2.0 \\
\hline TK-a-12.5 & 12.5 & & 2.5 \\
\hline TK-a-15.0 & 15 & & 3.0 \\
\hline TK-a-20.0 & 20 & & 4.0 \\
\hline TK-a-25.0 & 25 & & 5.0 \\
\hline
\end{tabular}

\subsection{Tanks under Vacuum Pressure}

\subsubsection{Linear Bifurcation Analysis (LBA)}

The lowest eigenvalue at which the shell may buckle into a different deformation mode can be obtained by LBA. The buckling mode results can be used as an initial geometric imperfection in the nonlinear analysis [27].

A summary of LBA results is shown in Fig. 5 considering the lowest positive eigenvalue in all studied configurations. However, for TK-a after 25 years, $\lambda_{c}$ is reduced to $28.6 \%$ of the as-new tank buckling load.

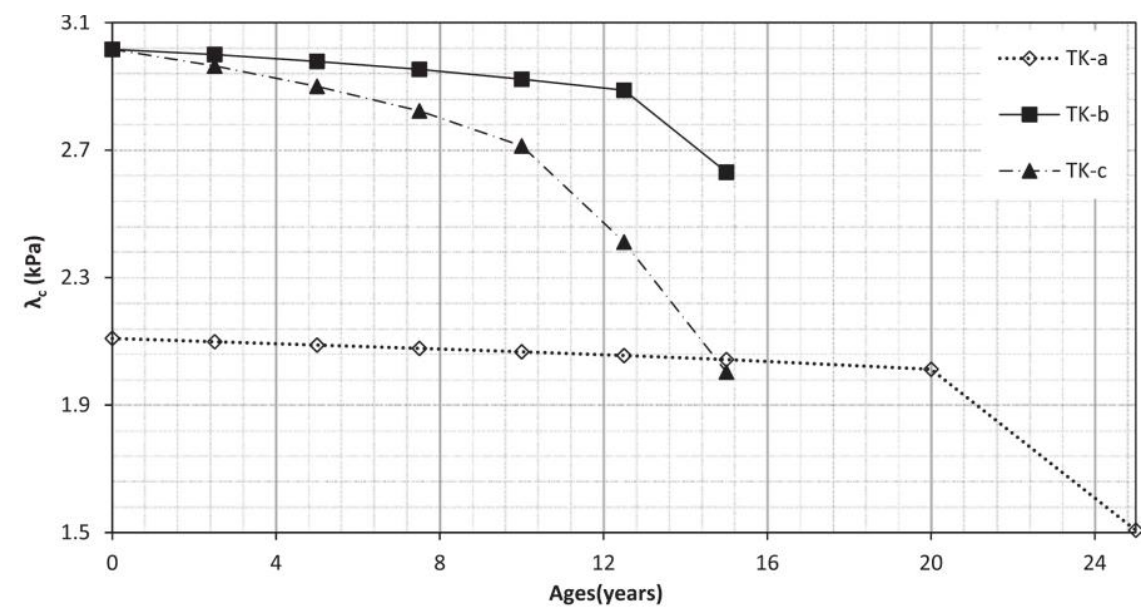

Fig. 5: LBA results: a comparative view of the TK-a, TK-b and TK-c buckling loads in different ages

\subsubsection{Geometrically Nonlinear Analysis (GNA or GNIA)}

The same finite element models as in LBA were used in the geometrically nonlinear analysis of the both perfect and imperfect tanks (GNA and GNIA). Eigenmode-affine imperfections (i.e., geometric imperfections having the same shape as the eigenmodes in LBA) were used. The amplitude $\xi$ of the imperfection was assumed as $\xi=0.5 t_{\min }, \xi=0.75 t_{\min }$ and $\xi=1.0 t_{\min }$, where $t_{\min }$ is the thinner course thickness (top course in the tapered cylindrical shell for as-new tank).

The result curves of imperfection-sensitivity (maximum load in an equilibrium path vs. imperfection amplitude) are shown in Fig. 6 (The force is obtained from the load, which is applied incrementally, and the displacement shown is the radial displacement of the node where the largest deformation occurs): for each tank, all curves have similar trends but at different values of maximum loads. Thus, for each tank, the sensitivity slope is seen to be similar to that of a newly constructed tank. It is clear that all tanks are very sensitive to the magnitude of imperfection. For example, the buckling resistance has been reduced by $23 \%$ for an imperfection level of $\xi / t_{\min }=0.5$ for tank TK-b-00.0.

\subsection{Tanks under Wind Pressure}

In order to study the fundamental and initial postcritical equilibrium path followed by the structure, the loaddisplacement curves were computed by selecting a node on the windward meridian and in the wind direction. 
The critical buckling loads obtained from GNA are slightly lower than those from LBA, as depicted in Table 4.

Curves of imperfection-sensitivity (maximum load in an equilibrium path vs. imperfection amplitude) are shown in Fig. 7: for each tank, all curves have similar trends but at different values of maximum loads.

Table 4: Critical buckling load factor obtained from GNA.

\begin{tabular}{|c|c|c|c|c|c|c|c|c|}
\hline TK-a & $\begin{array}{c}\text { Critical } \\
\text { buckling } \\
\text { load factor } \\
\text { from GNA } \\
\left(\lambda_{c \mathrm{~g}}\right)\end{array}$ & $\begin{array}{c}\lambda_{c \mathrm{~g}} / \lambda_{c} \\
(\%)\end{array}$ & TK-b & $\begin{array}{l}\text { Critical } \\
\text { buckling } \\
\text { load factor } \\
\text { from GNA } \\
\quad\left(\lambda_{c \mathrm{~g}}\right)\end{array}$ & $\begin{array}{c}\lambda_{c \mathrm{~g}} / \lambda_{c} \\
(\%)\end{array}$ & TK-c & $\begin{array}{l}\text { Critical } \\
\text { buckling } \\
\text { load factor } \\
\text { from GNA } \\
\left(\lambda_{c \mathrm{~g}}\right)\end{array}$ & $\begin{array}{c}\lambda_{c \mathrm{~g}} / \lambda_{c} \\
(\%)\end{array}$ \\
\hline TK-a-00.0 & 2.88 & 99.9 & TK-b-00.0 & 3.97 & 98.8 & TK-c & 3.79 & 97.9 \\
\hline TK-a-05.0 & 2.82 & 99.1 & TK-b-05.0 & 3.87 & 98.7 & TK-c-05.0 & 3.57 & 98.2 \\
\hline TK-a-10.0 & 2.8 & 99.3 & TK-b-10.0 & 3.70 & 98.1 & TK-c-10.0 & 3.12 & 97.4 \\
\hline TK-a-15.0 & 2.76 & 99.1 & TK-b-15.0 & 2.94 & 94.2 & TK-c-15.0 & 2.27 & 96.3 \\
\hline
\end{tabular}

${ }^{a}$ All buckling load factors are in $\mathrm{kPa}$.
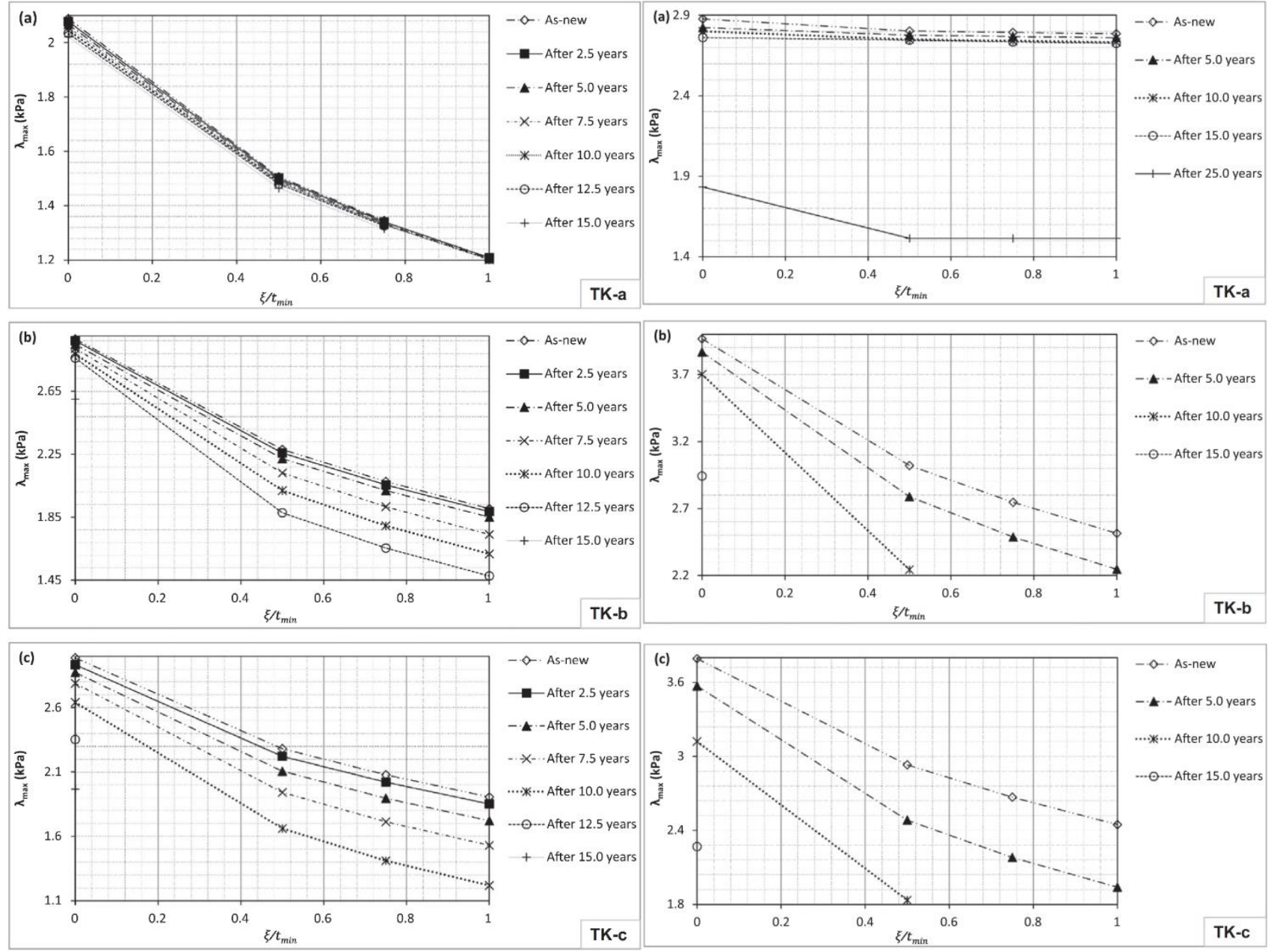

Fig. 6: Imperfection sensitivity of the tanks under vacuum pressure: (a) TK-a; (b) TK-b and (c) TK-c.

Fig. 7. Imperfection sensitivity of the tanks under wind pressure: (a) TK-a; (b) TK-b and (c) TK-c. 


\section{Conclusion}

A numerical study was carried out to investigate strengthening effect of spiral stairway on the buckling behavior of of anchored steel cylindrical tanks subjected to external pressures (wind and vacuum pressures). In addition, the effect effect of the corrosion and aging on the buckling behavior of aboveground steel cylindrical tanks subjected to external external pressures were studied. Comparative evaluations of results, lead to the following conclusions:

1. Under wind pressure, the spiral stairway improves the buckling strength of tank wall significantly. It seems that the spiral stairway acts as an oblique stiffener on the tank wall.

2. The strengthening effect of circumferential stairway on the buckling resistance of tanks under wind pressure increases as the aspect ratio increases.

3. When the angle between wind direction and the line connecting the center of stairway to the tank cylinder axis perpendicularly is $-15^{\circ} \sim 25^{\circ}$ for $\mathrm{TK}-\mathrm{a}^{\mathrm{s}},-15^{\circ} \sim 40^{\circ}$ for $\mathrm{TK}-\mathrm{b}^{\mathrm{s}}$ and $-5^{\circ} \sim 60^{\circ}$ for TK- $\mathrm{c}^{\mathrm{s}}$, the buckling resistance of the conical roof tanks increases $4 \% \sim 13.5 \%, 3 \% \sim 21.3 \%$ and $3 \% \sim 22 \%$, respectively. These values change to $4 \%$ $\sim 12 \%, 12 \% \sim 42 \%$ and $20 \% \sim 73 \%$ for TK-a ${ }^{\text {os }}$, TK-b ${ }^{\text {os }}$ and TK-c ${ }^{\mathrm{os}}$ (open-top tanks), respectively. Therefore, as the aspect ratio of the tanks increases, the stairway can strengthen larger portion of the tank wall. In addition, by choosing appropriate circumferential position for spiral stairway considering regional prevailing wind direction, designers can use this added strength as a safety margin.

4. Since the fatigue failure happens as a result of repetition of maximum stress experienced by the specimen, by choosing appropriate circumferential position for spiral stairway considering regional prevailing wind direction, number of experienced maximum stress can be decreased considerably. Therefore, spiral stairway can improve fatigue life.

5. Based on the results, the strengthening effect of the circumferential stairway is significant and should be considered in future editions of design codes.

6. Contrary to the case of wind loading, the stairway has negligible effect on buckling resistance of tanks under vacuum pressure. However, it changes the buckling modes of tanks significantly under uniform external pressure and it can cause a dramatic decline of buckling deformation in locations around the stairway.

7. Since the stiffness of the beam stairway is smaller than that of real one, the effect of the model stairway on the buckling behavior can be defined as a lower bound for real stairway effect. Therefore, this kind of simplification in spiral stairway modeling can be used in practical design of steel cylindrical tanks.

8. Excessive thinning of the upper part of the tank due to corrosion has a marked effect on the type of buckling failure.

9. The corrosion degradation of the upper parts of the tank also has a considerable effect on the critical buckling load. For vacuum loading, after only $3 \mathrm{~mm}$ thickness reduction (15 years of degradation based on assumed corrosion rate), critical buckling loads are reduced by as much as $12.8 \%$ in the medium height tank and $33.6 \%$ in the tall tank. Reduction in buckling pressure of approximately $28.6 \%$ is found for the short tank after 25 years of corrosion.

10. Under wind pressure, the critical buckling loads are reduced by as much as $22.2 \%$ in the medium height tank and $39.2 \%$ in the tall tank after 15 years of corrosion. For the short tank, reduction of buckling load is $32.5 \%$ after 25 years of corrosion.

11. Based on the comparison of results between GNA and LBA, it is believed that the linear bifurcation analysis is a good indicator for buckling load. Therefore, the lowest eigenvalue load constitutes an upper bound for geometrically nonlinear buckling load.

12. Upper part corrosion of the tanks can suddenly reduce the buckling strength and without any warning.

13. The corrosion sensitivity of tanks under wind load is higher than that of tanks under uniform external pressure.

\section{References}

[1] BS EN 14015-2004. "Specification for the design and manufacture of site built, vertical, cylindrical, flat-bottomed, above ground, welded, steel tanks for the storage of liquids at ambient temperature and above," British Standard $14015 ; 2004$.

[2] O. Zeybek, C. Topkaya and J. M. Rotter, "Stress resultants for wind girders in open-top cylindrical steel tanks," Engineering Structures, 196:330-347, 2019. 
[3] W. Jing, H. Feng and X. Cheng, "Dynamic responses of liquid storage tanks caused by wind and earthquake in special environment," Applied Sciences, 9:376-388, 2019.

[4] P. Pavlovic, R. Folic, V. Radonjanim, M. Tatomirovic, "The testing and repair of steel silo," Constr Build Mater, 11(5):353-63, 1997.

[5] F. G. Flores, L. A. Godoy, "Buckling of short tanks due to hurricanes," Eng Struct, 20(8):752-60, 1998.

[6] R. C. Jaca, L. A. Godoy, "Wind buckling of metal tanks during their construction" Thin-Walled Structures, 48(6):4539, 2010.

[7] A. Zingoni, "Liquid-containment shells of revolution: A review of recent studies on strength, stability and dynamics"” Thin-Walled Structures, 87:102-114, 2015.

[8] L. A. Godoy, "Buckling of vertical oil storage steel tanks: Review of static buckling studies," Thin-Walled Structures, 103:1-21, 2016.

[9] Y. Zhao, Y. Lin, "Buckling of cylindrical open-topped steel tanks under wind load," Thin-Walled Structures, 79:8394, 2014.

[10] G. Portela, L. A. Godoy, "Wind pressures and buckling of cylindrical steel tanks with conical roof," Journal of Construction Steel Research, 61(6):786-807, 2005.

[11] G. Portela, L. A. Godoy, "Wind pressures and buckling of cylindrical steel tanks with dome roof," Journal of Construction Steel Research, 61(6):808-824, 2005.

[12] Y. Lin, Y. Zhao. "Wind loads on fixed-roof cylindrical tanks with very low aspect ratio," Wind and Structures, 18(6):651-668, 2014.

[13] M. Rastgar and H. Showkati, "Buckling Behavior of cylindrical steel tanks with concavity of vertical weld line imperfection," Journal of Construction Steel Research, 61:289-299, 2018.

[14] C. De Paor, D. Kelliher, K. Cronin, W. Wright, S. G. McSweeney, "Prediction of vacuum-induced buckling pressures of thin-walled cylinders," Thin-Walled Structures, 55:1-10, 2012.

[15] L. Chen, J. M. Rotter, C. Doerich-Stavridis, "Practical calculations for uniform external pressure buckling in cylindrical shells with stepped walls," Thin-Walled Structures, 61:162-168, 2012.

[16] M.A. Al-Kashif, H. Ramadan, A. Rashed, M.A. Haroun, "Effect of FRP composites on buckling capacity of anchored steel tanks," Steel Comp. Struct., 10(4):361-371, 2010.

[17] M.J. Lewandowski, M. Gajewski, M. Gizejowski, "Numerical analysis of influence of intermediate stiffeners setting on the stability behaviour of thin-walled steel tank shell," Thin Walled Struct., 90, 119-127, 2015.

[18] S. Yousefi Khatuni and H. Showkati, "Buckling behaviour of semi-scale steel tank with carbon fiber reinforced polymer ring subjected to lateral uniform pressure loading," International Journal of Engineering, 32:1407-1415, 2019.

[19] A. Groysman, "Corrosion in systems for storage and transportation of petroleum products and biofuels," In: Proceeding of the NACE Corrosion 2015 Conference and Exposition, Dallas, Texas, USA; paper 5455, pp. 1-21, 2015.

[20] A. Groysman, "Corrosion in Systems for Storage and Transportation of Petroleum Products and Biofuels: Identification, Monitoring and Solutions," Springer, Dordrecht, 2014.

[21] M. L. Medvedeva, T. D. Tiam, "Classification of corrosion damage in steel storage tanks," Chemical and Petroleum Engineering, 34(9-10):620-622, 1998.

[22] A. Zagórski, H. Matysiak, O. Tsyrulnyk, O. Zvirko, H. Nykyforchyn, K. Kurzydłowski, "Corrosion and stresscorrosion cracking of exploited storage tank steel," Material Science, 40(3):113-7, 2004.

[23] I. Hajro, D. Hodžić, P. Tasić, "Integrity assessment of aboveground oil storage tanks due to the corrosion metal loss," J Trend in the Development in Machinery and Associated Technology, 18:91-94, 2014.

[24] J. C. Virella, L. A. Godoy, L. E. Suarez, "Fundamental modes of tank-liquid systems under horizontal motions," Engineering Structures, 28:1450-61, 2006.

[25] ABAQUS v6.9. Simulia. Unified FEA. Dassault Systems. Warwick, Rhode Island. USA, 2009.

[26] AS/NZS. Structural Design Actions, Part 2 - Wind Actions, Australian/New Zealand Standards 1170.2:2011, Sydney: 2011.

[27] Eurocode 3. Design of steel structures-Part 1-6, strength and stability of shell structures. European Standard EN 1993-1-6;2007. 